\title{
Influência de longos offsets no cálculo da correção estática
}

\author{
Paloma H. L. Fontes, Wilker E. Souza, Rafael R. Manenti e Milton J. Porsani CPGG/IGEO/UFBA \& INCT-GP/CNPq/Brasil
}

Copyright 2016, SBGf - Sociedade Brasileira de Geofísica.

Este texto foi preparado para a apresentação no VII Simpósio Brasileiro de Geofísica, Ouro Preto, 25 a 27 de outubro de 2016. Seu conteúdo foi revisado pelo Comitê Técnico do VII SimBGf, mas não necessariamente representa a opinião da SBGf ou de seus associados. É proibida a reprodução total ou parcial deste material para propósitos comerciais sem prévia autorização da SBGf.

\begin{abstract}
In this paper, we used the first breaking picking of the seismograms to obtain the velocities of the low-velocity zone (LVZ) and of the lower low-velocity zone (sub-LVZ), to calculate the static corrections. The near offsets brings us information about the weathered layer (LVZ), and the long offsets about the sub-LVZ. We show that it is not necessary to pick the first break along of all seismogram, since in the longer offsets the refractions of the subLVZ are not recorded, but the reflections that arrive at receivers, before shallow refractions. Thereby, the method discussed in this paper proposes the first break picking only in the offsets that include shallow refractions, so the calculation of static corrections will only use the information of interest, and therefore, this will facilitate and speed up the static correction, which is an important stage of seismic processing. The results of corrections show that the method works well, making first break more linearized and improving continuity of the reflections.
\end{abstract}

\section{Introdução}

A correção estática corresponde a um deslocamento em tempo aplicado ao traço sísmico, o qual sofreu efeitos causados pela Zona de Baixa Velocidade (ZBV) e pela variação da topografia.

Tem por objetivo corrigir os tempos de trânsito das reflexões sísmicas que sofrem alterações por não terem sido feitas em uma superfície de topografia constante e por conterem material de baixa velocidade presente (Cox, 1999).

Existem alguns métodos para o cálculo das correções estáticas: levantamento poço-acima (uphole survey); refração rasa; primeiras quebras dos sismogramas de reflexão (Cunha, 2010).

Recentemente esse tópico foi alvo de pesquisa de alguns autores como Souza (2014), Cunha (2010), Amorim (2007), Cox (1999), demonstrando assim a importância dessa etapa para o processamento sísmico.

No presente trabalho, apresentamos o método referido anteriormente no cálculo da correção estática. Para demonstração, utilizamos alguns tiros da linha sísmica regional $R L 001$ - 09 da Bacia do Parnaíba.

Os dados sísmicos utilizados foram cedidos pela BP Energy do Brasil (BP) no ano de 2015 para pesquisas de natureza acadêmica através do projeto PABIP.

\section{Metodologia e Problema Investigado}

O método utilizado para a obtenção das correções estáticas no presente trabalho foi feito através das primeiras quebras dos sismogramas de reflexão.

Parâmetros muito importantes para o cálculo da correção estática são obtidos através das primeiras informações do sismograma. Os sinais captados pelos geofones trazem informações da onda direta e das ondas refratadas criticamente, as quais, consequentemente, nos trarão as velocidades da ZBV nos offset mais curtos e a velocidade da sub-ZBV (camada subsequente à zona de intemperismo) nos offset mais longos. Uma vez que temos tais informações, podemos nos utilizar delas para calcular a espessura da camada intemperizada.

Em uma primeira etapa a ZBV é removida, de modo que sua base torna-se a nova superfície de referência. Ou seja, é como se os dados fossem coletados tendo a base da ZBV como a nova topografia; esta é conhecida como correção de intemperismo.

A etapa seguinte é utilizada para ajustar os dados a uma nova superfície de referência (datum), conhecida como correção de elevação, que se utiliza de informações da topografia e da velocidade de reposição.

Se o datum de referência está localizado abaixo da base da ZBV, a velocidade de reposição é normalmente calculada como velocidade da sub-ZBV. Se o datum de referência estiver acima da base da $Z B V$, uma velocidade próxima à velocidade da ZBV é utilizada como velocidade de reposição.

Considerando o modelo geológico ilustrado na Figura 1a, para uma interface horizontal profunda, a fonte sísmica $S$ libera energia que atingirá a superfície através de raios das ondas diretas, refletidas e refratadas. Os raios das ondas diretas caminham próximo à superfície com velocidade $V_{1}$ ao longo de uma linha reta até o geofone, sem interação com interfaces.

Sendo $X$ a distância entre a fonte $S$ e o receptor $R$, o tempo de percurso de um raio de onda direta é dado por:

$$
t_{\text {direta }}=\frac{X}{V_{1}}
$$

Considerando $X$ a distância entre a fonte $S$ e o receptor $R$, $V_{1}$ a velocidade do meio acima da interface refletora e $Z$ a espessura da ZBV, o tempo de percurso para os raios refletidos é dado por:

$$
t_{\text {refletida }}=\frac{\sqrt{X^{2}+4 Z^{2}}}{V_{1}}
$$

$O$ raio refratado que sai da fonte $S$ percorre o caminho (SA) dentro da camada superior com velocidade $V_{1}$, incide 
na interface com ângulo crítico $\left(i_{c}\right)$ fazendo o trajeto $(\mathrm{AB})$ com velocidade $V_{2}$ e em seguida retornando à superfície obliquamente com o ângulo crítico $\left(i_{c}\right)$ pela trajetória (BR). O tempo de percurso de um raio refratado é dado por:

$$
t_{\text {refratada }}=\frac{X}{V_{1}}+\frac{2 Z \cos \left(i_{c}\right)}{V_{1}}
$$

A Figura $1 \mathrm{~b}$ ilustra as curvas do tempo de percurso em função do offset das ondas diretas, refletidas e refratadas (curva tempo distância). Analisando as curvas, três importantes considerações podem ser feitas:

a) A onda refratada só atingirá a superfície a partir de uma separação mínima fonte-receptor conhecida como distância crítica $\left(X_{\text {crit }}\right)$. $\quad \mathrm{Em} X_{\text {crit }}$ os raios refletidos e refratados seguem a mesma trajetória, coincidindo os tempos de percursos. Igualando as equações (2) e (3) e resolvendo $X_{\text {crit }}$, temos que:

$$
X_{\text {crit }}=2 Z \frac{V_{1}}{\sqrt{V_{2}^{2}-V_{1}^{2}}}
$$

b) A partir de determinado offset, os raios refratados serão sempre os primeiros a serem detectados. Em $X_{\text {cros }}$ as ondas diretas e refratadas se cruzam neste ponto, ou seja, elas possuem o mesmo tempo de percurso neste local específico. Igualando as equações (1) e (2) e resolvendo $X_{\text {cros }}$, temos que:

$$
X_{c r i t}=2 Z \sqrt{\frac{V_{1}^{2}+V_{2}^{2}}{V_{2}^{2}-V_{1}^{2}}}
$$

c) Nem sempre os parâmetros $X_{\text {crit }}$ e $X_{\text {cros }}$ são bem definidos, nesses casos, há uma outra formulação para o cálculo da espessura da ZBV, que é através do tempo de intercepção $\left(t_{0}\right)$, o qual corresponde à extrapolação do alinhamento da reta do raio refratado até a posição $X=0$, como podemos verificar no gráfico da Figura 1b. A espessura, neste caso, coincide com a profundidade $Z$ do refrator que é determinado pelo tempo de intercepção $\left(t_{0}\right)$, e é dada pela equação:

$$
Z=\frac{t_{0} V_{1} V_{2}}{\sqrt{V_{2}^{2}-V_{1}^{2}}}
$$

Para o cálculo da correção estática, os raios sísmicos são tratados como sendo verticais ao passarem na ZBV, o que traz a propriedade da consistência superficial, na qual as correções a serem feitas dependem apenas das distâncias fonte-receptor, sem levar em conta o trajeto do raio sísmico. A partir daí, podemos notar a importância do offset para o cálculo da correção estática.

A velocidade da ZBV $\left(V_{1}\right)$ e a velocidade da sub-ZBV $\left(V_{2}\right)$, as quais são utilizadas no cálculo da espessura $(Z)$ da ZBV, podem ser identificadas a partir dos picks de primeira quebra nos sismogramas de reflexão sísmica. A $V_{1}$ pode ser obtida a partir do cálculo da inclinação da reta (Figura 1b) equivalente às chegadas da onda direta, e $V_{2}$ a partir do inverso do gradiente da reta dos tempos de trânsito da onda refratada nesta interface.
A Figura 2 ilustra um sismograma de reflexão, no qual estão indicadas algumas velocidades das primeiras quebras. Pudemos perceber que nos offset mais curtos, a velocidade é baixa, de aproximadamente $1277 \mathrm{~m} / \mathrm{s}$ (interpretada como velocidade da ZBV); com o aumento gradual do offset a velocidade passa a ser de $3133 \mathrm{~m} / \mathrm{s}$ (interpretada como a velocidade das refrações rasas), e nos offset mais distantes, observa uma velocidade de $5460 \mathrm{~m} / \mathrm{s}$ (interpretada como velocidades de refrações ou reflexões em interfaces profundas)

Para não fazermos uso de informações que se referem às velocidades de camadas profundas para cálculo da espessura da ZBV e posteriormente no cálculo dos erros estáticos, utilizaremos apenas os picks de primeira quebra referentes apenas aos offset que contemplem às refrações rasas, os quais possuem informações da camada intemperizada.

Para tanto, fizemos o cálculo da correção estática nos offset curtos e comparamos com o cálculo da correção estática nos offset longos, os quais trazem informações da ZBV e outras informações subjacentes à zona de intemperismo (as quais não seriam necessárias para o cálculo)

\section{Aplicação e Resultados}

A correção estática feita em offset curtos e longos foi aplicada em um dado sísmico terrestre da Bacia do Parnaíba, adquirido pela British Petroleum (BP) em conjunto com a Global Geophysical Services Incorporated. O dado possui um arranjo split-spread simétrico, com um total de 200 traços. A distância entre receptores, entre pontos de vibração e offset mínimo é de $25 \mathrm{~m}$. O dado possui 1251 amostras, com intervalo de amostragem de 4 milissegundos, totalizando 5 segundos de tempo de registro.

Para perceber a influência dos longos offset no cálculo da correção estática, aplicamos as seguintes etapas de processamento:

- Leitura e Conversão do Dado Seg-Y;

- Montagem e Aplicação da Geometria;

- Picking das primeiras quebras do sismograma;

- Cálculo da Correção Estática;

- Aplicação da Correção Estática.

O desenvolvimento deste trabalho foi feito no pacote comercial de processamento SeisSpace, o qual disponibiliza de várias opções para o cálculo da correção estática; foi utilizado o Refraction Static Calculation, o qual, calcula a velocidade do refrator (sub-ZBV), o tempo de atraso causado pelo trânsito na ZBV (delay time), a profundidade do modelo e os tempos de correção estática das fontes e dos receptores com base em um arquivo de picking fornecido pelo usuário. A vantagem de usar tal chave é que não há especificações quanto ao tipo de geometria da aquisição, podendo utiliza-la mesmo que a geometria seja sinuosa. A qualidade da estática calculada está diretamente relacionada à qualidade dos picking das primeiras quebras. 
Fornecendo alguns parâmetros de entrada, os procedimentos subsequentes para cálculo das estáticas podem ser esquematizados através das seguintes etapas:

1. Entrar ou calcular a velocidade média da ZBV $\left(V_{1}\right)$; ela será utilizada como velocidade da superfície ao topo do primeiro refrator;

2. Entrar com um intervalo de offset no qual será feito o cálculo das profundidades e velocidades referente ao refrator ao longo da linha;

3. Calcular a velocidade de refração (velocidade da subZBV);

4. Calcular o delay time (tempo de atraso) entre fonte e receptor

5. Calcular o modelo do refrator em profundidade, tendo como saída uma estimativa dos valores da espessura da ZBV; Calcular a estática de fonte e receptor até o datum final.

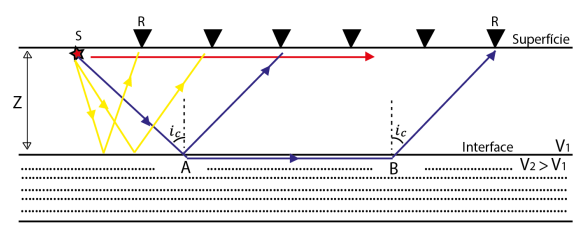

(a)

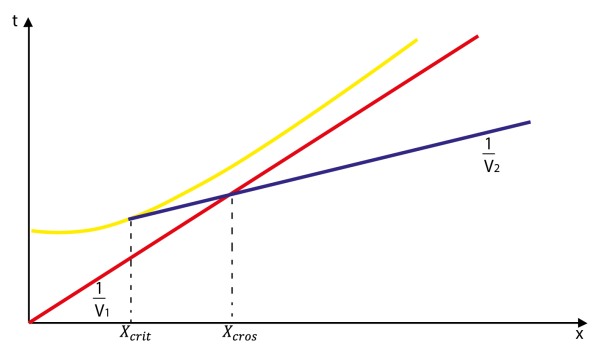

(b)

Figura 1: Trajetórias dos raios direto (vermelho) refletido (amarelo) e refratado (azul) em um modelo geológico de duas camadas (b); Curvas do tempo de trânsito para os raios direto (vermelho), refletido (amarelo) e refratado (azul) referentes a Figura 1a

No presente trabalho fizemos dois fluxos de processamento, utilizando 75 tiros em ambos. No primeiro fluxo aplicamos todas as etapas de processamento que foram descritas anteriormente; sendo que, no cálculo da correção estática desse, utilizamos como dado de entrada os picks que contemplam 875 metros (Figura 3a), tendo esse valor como offset máximo.

No fluxo seguinte, também fizemos todo o processo descrito anteriormente; sendo que, desta vez no cálculo da correção estática, utilizamos como dado de entrada os picks que contemplam 3750 metros (Figura 3b), tendo esse valor como offset máximo.

Os resultados dos cálculos feitos na etapa Refraction Static Calculation foram aplicados no dado com geometria, tanto no primeiro quanto no segundo fluxo). Como verificado pelas figuras $4 a$ e $4 b$, a espessura da ZBV calculada em um fluxo é diferente da calculada no segundo, o que faz com que a estática total seja distinta nos dois fluxos; isso comprova que os offset mais distantes irão influenciar no cálculo da correção estática. Os resultados da aplicação das correções estáticas em ambos os dados estão representados pelas figuras $5 \mathrm{a}$ e $5 \mathrm{~b}$.

\section{Discussão e Conclusões}

Após fazer os picks de primeira quebra nos tiros com offset longos e utilizar os mesmos para o dado com offset curto (respectivamente figuras $3 \mathrm{~b}$ e $3 \mathrm{a}$ ), e fazer o cálculo da correção estática utilizando tais situações, pudemos perceber uma aplicação do cálculo da correção estática de boa qualidade utilizando apenas os picks dos offset curtos (Figura 5a), onde indicamos com setas vermelhos os locais de melhora.

Podemos notar que no tiro representado na Figura $5 a$ a primeira quebra se tornou linear e algumas reflexões ficaram com continuidade significativamente melhor. Fazendo um balanço de perdas e ganhos na qualidade da aplicação da correção estática, pudemos perceber que com um número de picks que contemplem apenas as refrações rasas, obtivemos resultados satisfatórios com um menor tempo de processamento.

Assim, usando tal metodologia, temos como resultado um dado de boa qualidade, sem a necessidade de picks de primeira quebra em todos os traços do tiro; o que, por consequência, é uma maneira mais veloz e eficaz de fazer o cálculo da correção estática. Além disso, através do estudo das primeiras quebras do sismograma de reflexão, pudemos perceber que precisamos de informações da ZBV e das refrações rasas para o cálculo, logo, é uma maneira teoricamente mais correta de utilizarmos tais informações.

\section{Agradecimentos}

Agradecemos ao fomento à pesquisa dado pelo CNPq/INCT-GP/CNPQ/MCTI, PETROBRAS; a Landmark pela licença do pacote de dados SeisSpace; à BP/PABIP e à Global Geophysical Services Incorporated pela concessão dos dados utilizados e ao LAGEP/CPGG pela viabilização de suas instalações físicas usadas para produção do artigo.

\section{Referências}

Amorim, W. N. De e Gontijo, M. S, 2007. Correções Estáticas, PETROBRAS, publicação interna.

Cox, M. J. G. 1999. Static Corrections for Seismic Reflection Surveys. Society of Exploration Geophysicists, Oklahoma.

Cunha, R. S, 2010. Cálculo das correções estáticas. Trabalho de Graduação, Universidade Federal da Bahia, Salvador, Brasil.

Souza, W. E, 2014. Processamento CMP de Dados Sísmicos Levantados no Norte da Bacia do São Francisco utilizando o Pacote de Programas SeisSpace. Trabalho de Graduação, UFBA, Salvador, Brasil. 


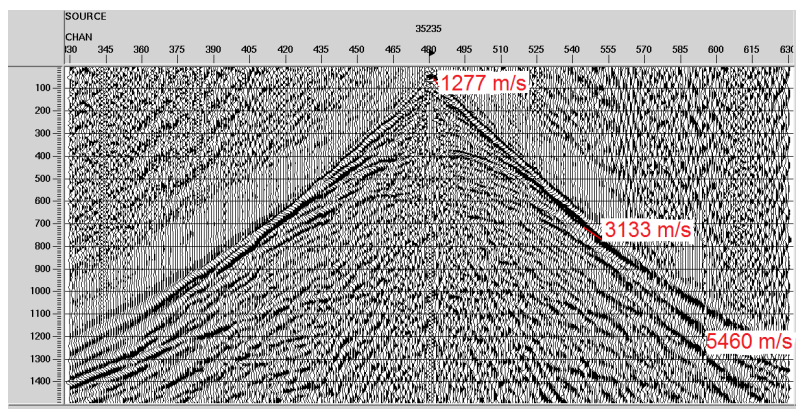

Figura 2: Sismograma ilustrando a variação das velocidades das primeiras chegadas com o offset, indicadas em vermelho.

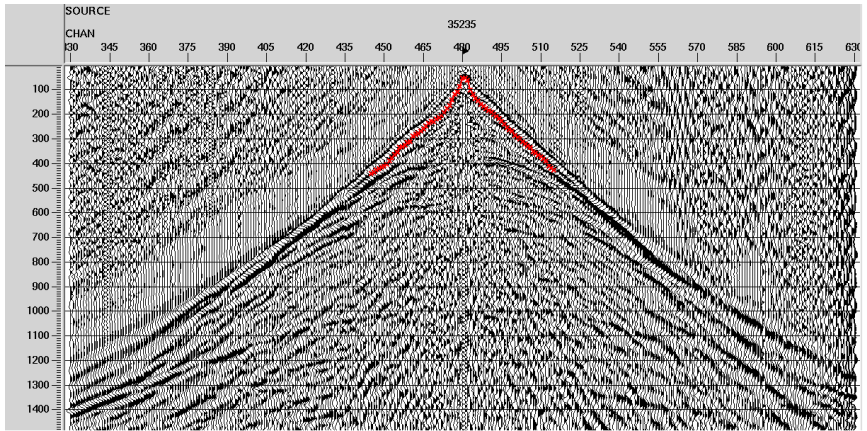

(a)

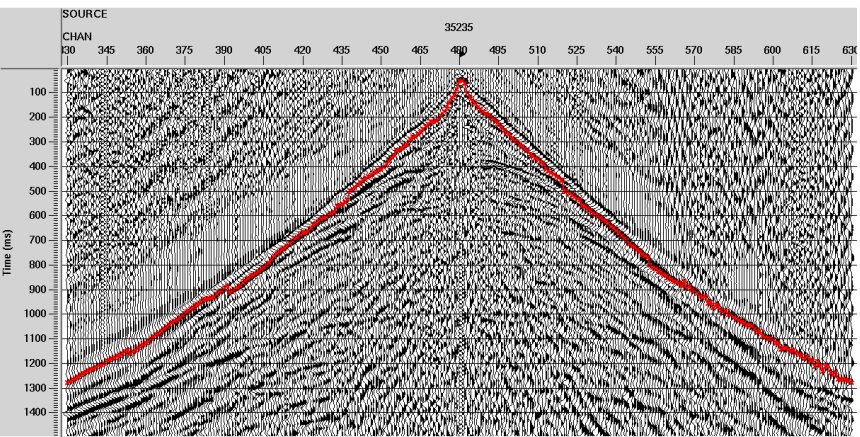

(b)

Figura 3: Dados com os picks (a) apenas nos offsets curtos e (b) nos offsets longos.

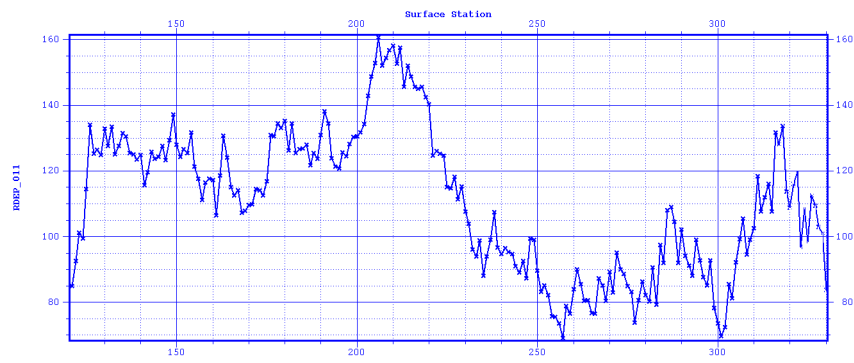

(a)

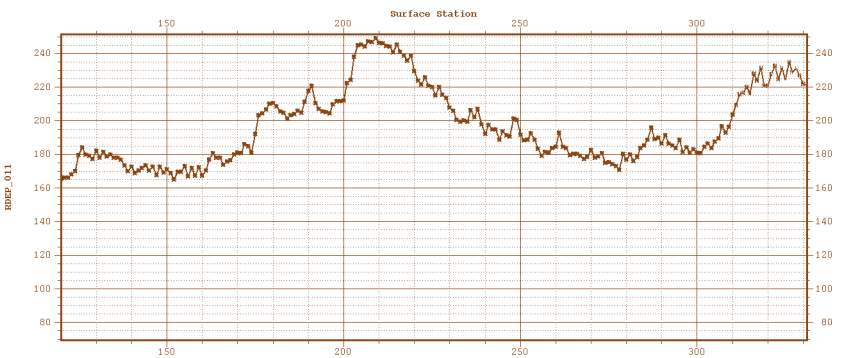

(b)

Figura 4: (a) Gráfico da espessura da ZBV calculado através dos picks em offsets curtos (referenciada na Figura 3a), (b) e em offsets longos (referenciada na Figura $3 b$ ). 


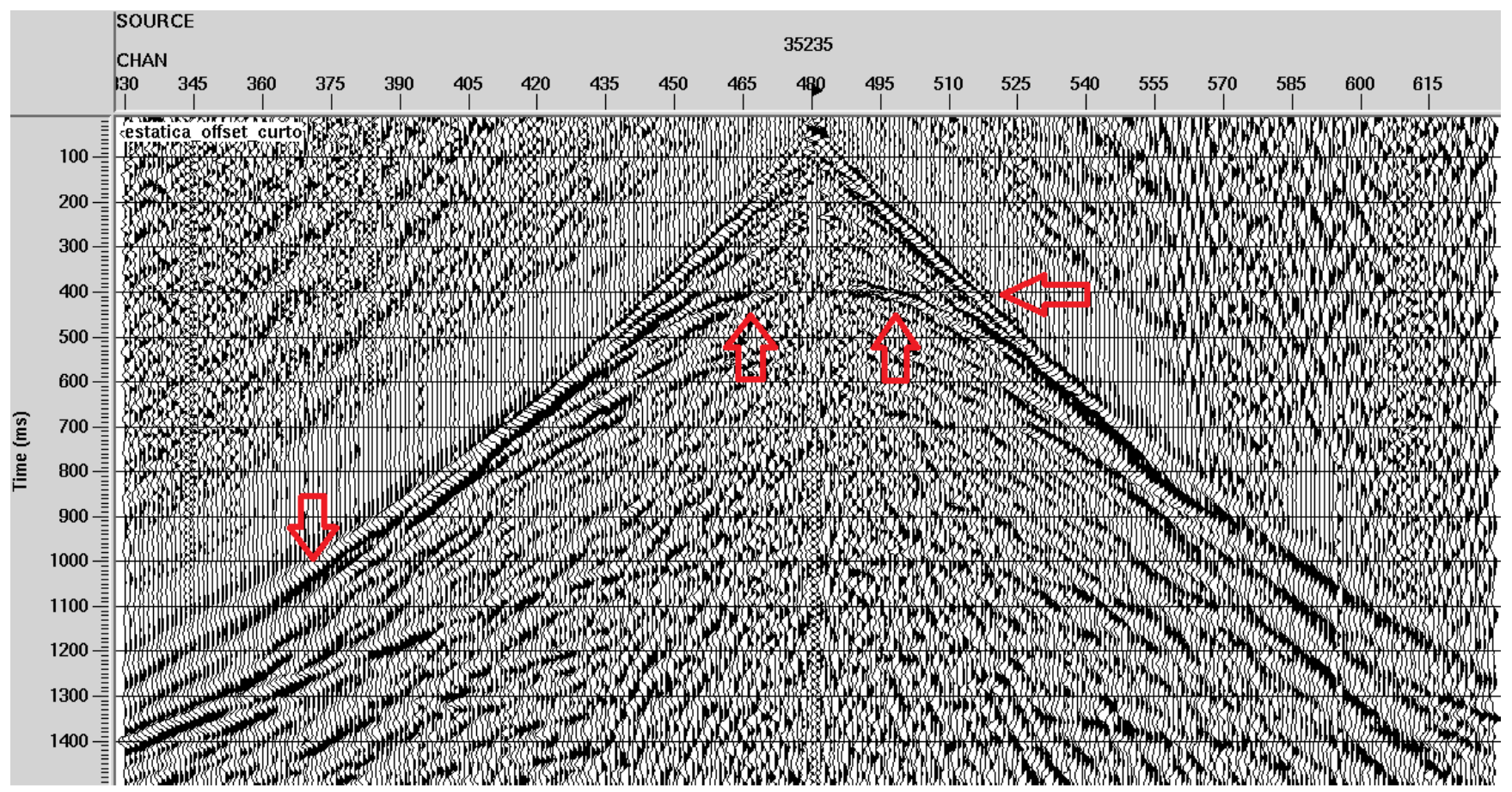

(a)

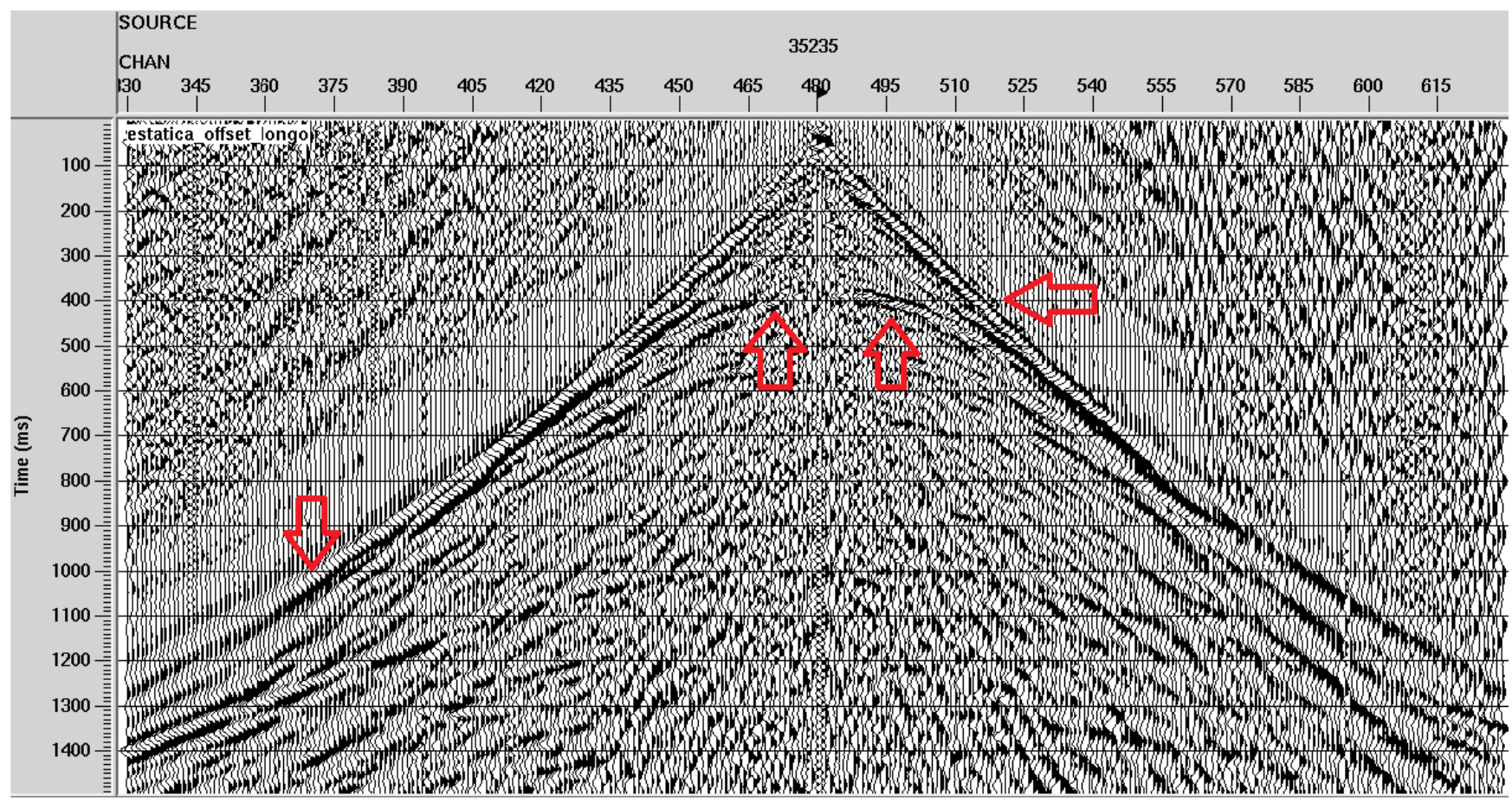

(b)

Figura 5: (a) Dado com correção estática utilizando os picks nos offsets curtos e as melhoras indicadas pelas setas vermelhas; (b) dado com correção estática utilizando os picks nos offsets longos. 